УДК 621.74 .04

\title{
Import-Substituting Release Coatings for Molds of Low-Pressure Casting
}

\author{
Aleksandr A. Kosovich*a, \\ Tatiana R. Gilmanshina ${ }^{a}$, Tatiana A. Bogdanovab, \\ Aleksandr V. Cheglakov ${ }^{b}$, Pavel Yu. Barbitsky ${ }^{b}$, \\ Svetlana I. Lytkina ${ }^{a}$ and Evgeny G. Partyko \\ ${ }^{a}$ Siberian Federal University \\ 79 Svobodny, Krasnoyarsk, 660041, Russia \\ ${ }^{b} K \& K$ ltd \\ 3 Berezina, Krasnoyarsk, 660020, Russia
}

Received 18.01.2016, received in revised form 26.03.2016, accepted 19.07.2016

The results of development of release coatings of molds for casting light-alloy wheels under low pressure are presented. Efficiency of the developed coatings in comparison with the applied foreign analogs is shown; results of their industrial approbation are given.

Keywords: import-substitution, release coating, casting under low pressure, mold, light-alloy wheels, castability.

Citation: Kosovich A.A., Gilmanshina T.R., Bogdanova T.A., Cheglakov A.V., Barbitsky P.Yu., Lytkina S.I., Partyko E.G Import-substituting release coatings for molds of low-pressure casting, J. Sib. Fed. Univ. Eng. technol., 2016, 9(5), 686-692. DOI: 10.17516/1999-494X-2016-9-5-686-692.

(C) Siberian Federal University. All rights reserved

* Corresponding author E-mail address: a-herz@mail.ru,gtr1977@mail.ru 


\title{
Импортозамещающие разделительные покрытия для пресс-форм литья под низким давлением
}

\author{
А.А. Косович ${ }^{a}$, Т.Р. Гильманшина ${ }^{a}$, \\ T.А. Богданова ${ }^{\tilde{0}}$, А.В. Чеглаков ${ }^{\sigma}$, \\ П.Ю. Барбицкийб ${ }^{\circ}$ С.И. Лыткина ${ }^{a}$, Е.Г. Партыко ${ }^{a}$ \\ ${ }^{a}$ Сибирский федеральный университет \\ Россия, 660041, Красноярск, пр. Свободный, 79 \\ ${ }^{6} \mathrm{OOO}$ «KuK» \\ Россия, 660020, Красноярск, Березина, 3
}

\begin{abstract}
Представлены результаты разработки разделительных покрытий пресс-форм для литья легкосплавных дисков под низким давлением. Показана эффективность разрабатываемых составов в сравнении с применяемыми зарубежными аналогами, приведены результаты их промышленного опробования.
\end{abstract}

Ключевые слова: импортозамещение, разделительное покрытие, литье под низким давлением, пресс-форма, легкосплавные диски, жидкотекучесть.

\section{Введение}

В современных условиях зависимости промышленности от рыночной и политической обстановки в совокупности с отрицательной динамикой роста, наблюдаемой в российском производстве изделий из алюминия, с каждым годом все усложняется задача выпуска конкурентоспособной продукции с минимальными затратами [1].

В связи с этим освоение импортозамещающих технологий в настоящее время - основополагающее направление, реализуемое на многих металлургических заводах, выпускающих продукцию на основе алюминия, в т.ч. и на предприятии ООО «КиК» - крупнейшем в России и одном из ведущих в мире заводе по производству легкосплавных колесных дисков [2]. На предприятии ведется поиск технологий, повышающих качество поверхности дисков автомобильных колес за счет совершенствования процесса подготовки пресс-форм.

Одним из наиболее распространенных способов защиты поверхности пресс-форм от химического и теплового воздействия струи металла в производстве является использование разделительных покрытий [3].

Предпосылки проводимого исследования:

- сложность выбора исходных материалов покрытия из-за недостаточной изученности процессов, происходящих в системе «отливка - разделительное покрытие - рабочая поверхность пресс-формы»;

- неудовлетворенность производителей фасонной алюминиевой продукции имеющимися на рынке отечественными разделительными покрытиями;

- существенное увеличение стоимости готовой продукции при использовании на прессформах разделительных покрытий, закупаемых за рубежом (Англия, Германия);

- отсутствие в регионе производства подобных покрытий при имеющейся ресурсной базе.

$$
-687-
$$


Таким образом, цель данной работы заключается в разработке импортозамещающих разделительных покрытий для пресс-форм.

Достижение поставленной цели подразумевает выполнение задач по изучению влияния химического и фракционного составов наполнителей на свойства покрытий и влияния покрытий на качество поверхности дисков автомобильных колес, изготавливаемых методом литья под низким давлением.

\section{Образцы и методы исследования}

Работа выполнена на ООО «КиК» и в лабораториях ИЦМиМ СФУ.

В результате проведенных ранее исследований $[4,5]$ был предложен ряд составов разделительных покрытий на основе оксидов титана и алюминия, соли бария.

Технология приготовления покрытий заключалось в следующем. Пастообразные концентраты разрабатываемых покрытий и серийно применяемых на предприятии зарубежных аналогов разбавляли водой до нужной плотности, обеспечивающей их равномерное нанесение распылителем.

Общие и технологические свойства покрытий исследовали по ГОСТ 10772-78. Фотографии микроструктуры покрытий, нанесенных на металлические пластинки, получены с помощью инвертированного оптического микроскопа OLYMPUS GX51.

Оценка влияния покрытий на жидкотекучесть сплава АК12 проводилась при помощи спиральной металлической пробы по ГОСТ 16438-70.

\section{Обсуждение результатов}

Результаты исследований показывают, что увеличение содержания связующего по отношению к тонкодисперсному наполнителю в разработанных составах положительно сказывается на седиментационной устойчивости и приведенной прочности, что позволяет приблизиться и превзойти показатели зарубежных аналогов (табл. 1).

Общий более низкий уровень жидкотекучести обусловлен отличными от серийного покрытия теплофизическими свойствами и структурой слоя на поверхности формы (рис. 1, 2). При этом отмечается, что с увеличением содержания связующего жидкотекучесть сплава АК12 повышается.

Среди разработанных составов наибольшей применимостью обладает КП80: его оптимальные свойства обеспечиваются соотношением наполнителя и связующего, близким к $1: 1$.

Поэтому данный состав был опробован на литейном участке ООО «КиК», в ходе работы окрашивали одну из рабочих пресс-форм (рис. 3). Отливки колес определенной модели получали на одной и той же литейной машине, после чего они проходили отбраковку по рентгенконтролю.

Опытно-промышленные испытания продемонстрировали увеличение выхода годного при литье колеса выбранной модели с 95,44 до 96,56 \%, что является существенным показателем для данного производства.

Для повышения рабочих и технологических свойств покрытий (рис. 4-6), а также получения их более плотной структуры слоя на поверхности пресс-формы было изменено соот- 
Таблица 1. Сравнение свойств покрытий

\begin{tabular}{|c|c|c|c|c|c|c|c|}
\hline Свойство & \multicolumn{7}{|c|}{ Покрытие } \\
\hline Производитель & Германия & Англия & \multicolumn{5}{|c|}{ Разрабатываемые составы } \\
\hline Обозначение & H1 & D1 & КП60 & КП70 & КП80 & КП90 & КП100 \\
\hline $\begin{array}{l}\text { Содержание } \\
\text { связующего, \% }\end{array}$ & - & - & 44 & 47 & 50 & 53 & 56 \\
\hline Соотношение с водой & $4: 1$ & $6: 1$ & \multicolumn{5}{|c|}{$5: 1$} \\
\hline Плотность, кг/м ${ }^{3}$ & 1075 & 1070 & 1085 & 1085 & 1080 & 1075 & 1075 \\
\hline Вязкость, с & \multicolumn{7}{|c|}{10} \\
\hline $\begin{array}{l}\text { Седиментационная } \\
\text { устойчивость, \% } \\
\text { отметки через, ч: } \\
0,5 \\
1 \\
3 \\
7 \\
24\end{array}$ & $\begin{array}{c}100 \\
99 \\
99 \\
99 \\
98\end{array}$ & $\begin{array}{c}55 \\
15 \\
8 \\
8 \\
8\end{array}$ & $\begin{array}{l}77 \\
59 \\
22 \\
12 \\
12\end{array}$ & $\begin{array}{l}80 \\
67 \\
25 \\
20 \\
20\end{array}$ & $\begin{array}{c}83 \\
71 \\
31 \\
10 \\
7\end{array}$ & $\begin{array}{c}82 \\
64 \\
20 \\
4 \\
4\end{array}$ & $\begin{array}{c}78 \\
51 \\
12 \\
7 \\
7\end{array}$ \\
\hline $\begin{array}{l}\text { Приведённая } \\
\text { прочность, г/мм }\end{array}$ & 7830 & 8780 & 3960 & 5410 & 8850 & 8810 & 8780 \\
\hline $\begin{array}{l}\text { Жидкотекучесть } \\
\text { АК12, см }\end{array}$ & 45 & 43 & 28 & 32 & 34 & 37 & 40 \\
\hline
\end{tabular}

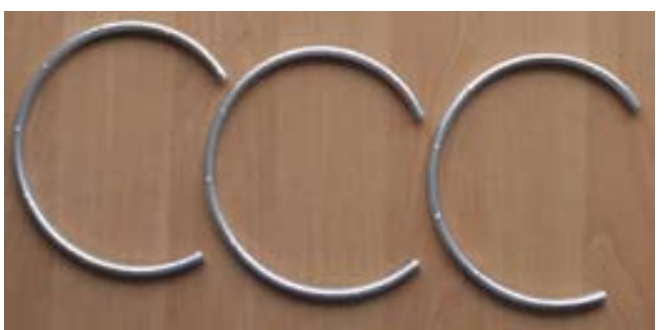

a

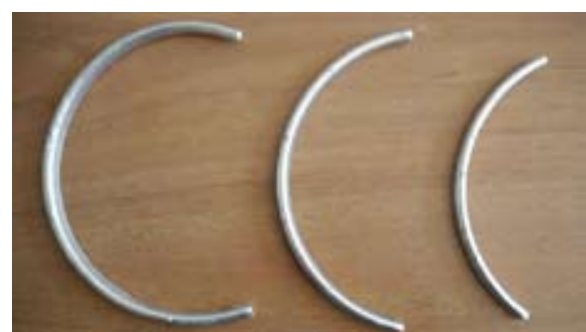

б

Рис. 1. Пробы жидкотекучести сплава АК12 в зависимости от нанесенного покрытия: a - серийное D1; б - разработанное КП 80

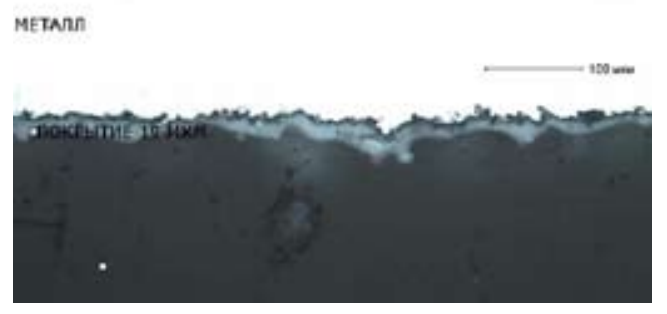

a

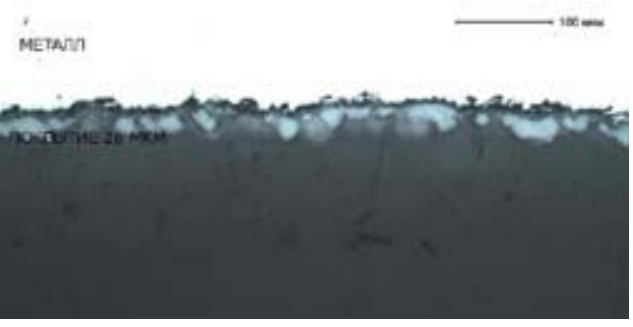

6

Рис. 2. Микроструктуры покрытий: а - серийное D1; б - разработанное КП80

$$
-689-
$$




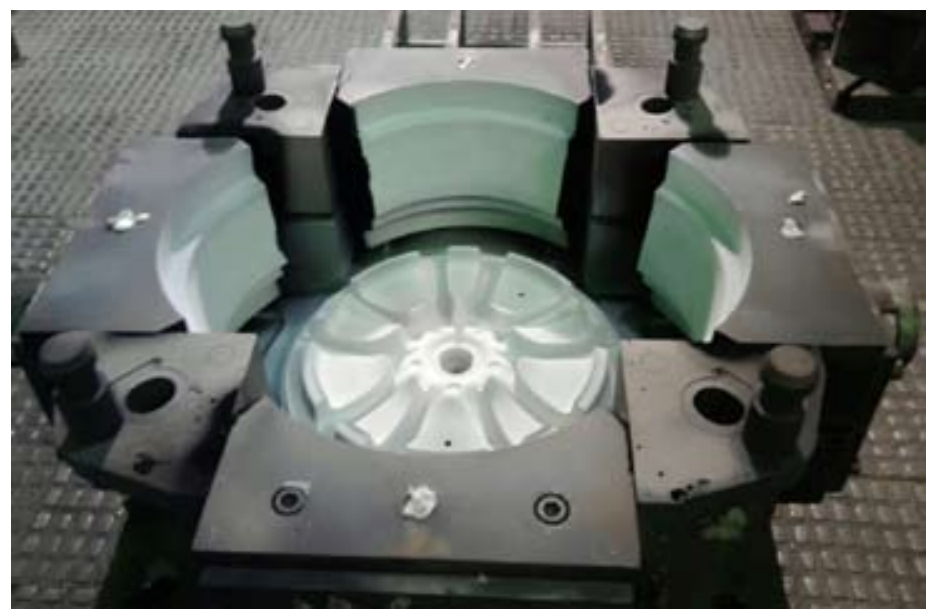

Рис. 3. Заводская пресс-форма, окрашенная опытным покрытием

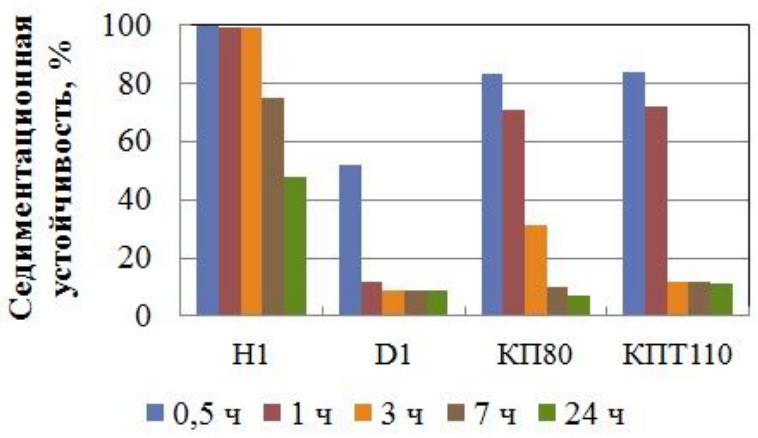

Рис. 4. Сравнение седиментационной устойчивости покрытий

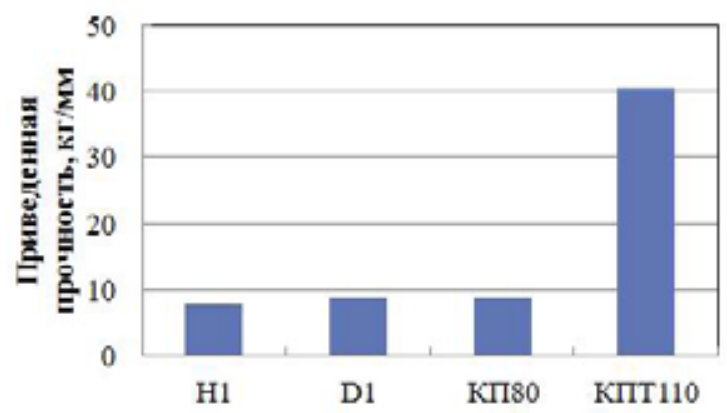

Рис. 5. Сравнение приведенной прочности покрытий

ношение компонентов КП80 и введены в его состав минеральные добавки тонкого помола, что позволило разработать покрытие КПТ110 (рис. 7).

Опытно-промышленные испытания покрытия КПТ110 показали: увеличение выхода, годного для двух моделей колес диаметром 17 , составило от 1,53 до 4,11 \%, для модели 


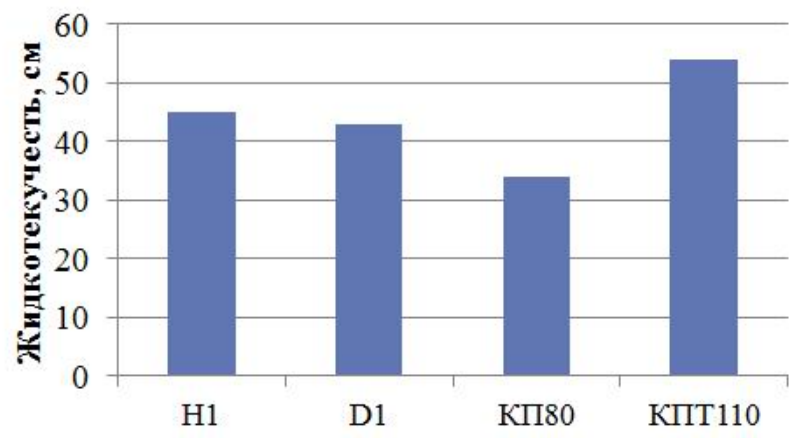

Рис. 6. Сравнение жидкотекучести АК12 в зависимости от нанесенного покрытия

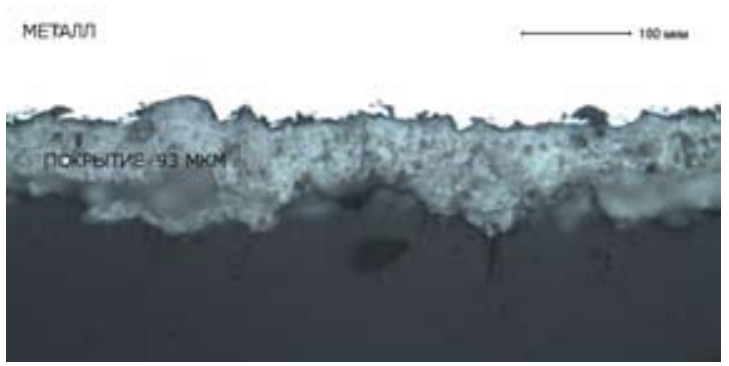

Рис. 7. Фотография микроструктуры покрытия

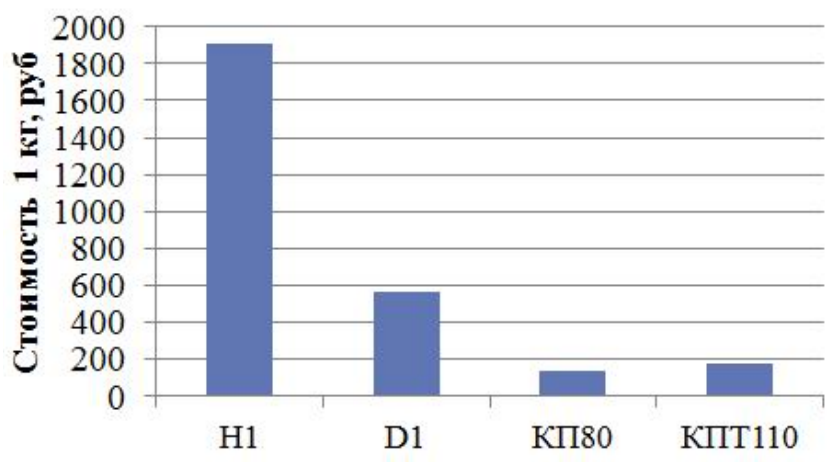

Рис. 8. Сравнение стоимости 1 кг концентрата покрытий

колеса диаметром 18 " - 10,35 \%. При этом данное покрытие, по предварительным расчетам, обладает в 3 раза меньшей себестоимостью, чем серийно используемый зарубежный аналог (рис. 8).

\section{Заключение}

В результате проведенной работы:

- определены свойства разделительных покрытий, применимых для литья автомобильных дисков под низким давлением; 
- разработан ряд экспериментальных составов разделительных покрытий, из которых выбран оптимальный;

- при литье колеса выбранной модели с использованием состава КП80 выход годного увеличен на $1,12 \%$;

- при опробовании покрытия КПТ110 установлено увеличение выхода годного для трех моделей колес, на 1,53, 4,11 и 10,35 \% соответственно;

- создан задел по разработке и внедрению технологии покрытий в промышленное производство дисков методом литья под низким давлением на ООО «КиК».

Таким образом, разработанное покрытие позволяет снизить простои пресс-форм в процессе литья, увеличить производительность, продлить срок службы пресс-форм по сравнению с зарубежными аналогами. В то же время разработанное покрытие дает возможность избежать брака в виде пористости на поверхности отливок, тем самым улучшая качество готовых колес.

Подана заявка на патентование разработанных и опробованных составов разделительных покрытий. Ведется работа над составами покрытий с повышенными изолирующими свойствами и смазывающим эффектом.

\section{Список литературы}

[1] Неменов А.М. События в цифрах и фактах. Металлург, 2014, 4, 17-28 [Nemenov A.M. Events by the numbers and facts. Metallurgist, 2014, 4, 17-28 (in Russian)]

[2] Богданова Т.А., Довженко Н.Н., Гильманшина Т.Р., Баранов В.Н., Чеглаков А.В., Меркулова Г.А., Лыткина С.И., Худоногов С.А., Косович А.А., Партыко Е.Г. Современные технологии изготовления дисков автомобильных колес. Современные проблемы науки и образования, 2014, 5; http://www.science-education.ru/pdf/2014/5/567.pdf [Bogdanova T.A., Dovzhenko N.N., Gilmanshina T.R., Baranov V.N., Cheglakov A.V., Merkulova G.A., Lytkina S.I., Khudonogov S.A., Kosovich A.A., Partyko E.G. Modern manufacturing techniques disc auto-mobile wheel. Modern problems of science and education, 2014, 5; http://www.science-education.ru/pdf/2014/5/567. pdf (in Russian)]

[3] Shi F. Ceramic Coatings - Applications in Engineering. Rijeka, 2012, 286 p.

[4] Барбицкий П.Ю., Косович А.А., Богданова Т.А., Гильманшина Т.Р., Довженко Н.Н. Возможность разработки высокотехнологичных покрытий пресс-форм для литья под низким давлением, Сборник тезисов докладов VI международного конгресса «Цветные металль и минераль - 2014», Красноярск, 2014, 366 [Barbitsky P.Yu., Kosovich A.A., Bogdanova T.A., Gilmanshina T.R., Dovzhenko N.N. Development of high-tech coatings of press moulds for casting under low pressure, Book of abstracts of the sixth international congress «Non-Ferrous metals \& Minerals2014», Krasnoyarsk, 2014, 366 (in Russian)]

[5] Барбицкий П.Ю., Богданова Т.А., Гильманшина Т.Р., Довженко Н.Н., Чеглаков А.В., Лыткина С.И., Косович А.А., Партыко Е.Г. Исследование влияния качества графита на покрытия пресс-форм для литья под низким давлением. Журнал СФУ. Техника и технологии, 2015, 8(5), 663-668 [Barbitsky P.Yu., Bogdanova T.A., Gilmanshina T.R., Dovzhenko N.N., Cheglakov A.V., Lytkina S.I., Kosovich A.A., Partyko E.G. The Research of Influence of Graphite Quality on Mold Coatings for Low-Pressure Die Casting. J. Sib. Fed. Univ. Eng. technol., 2015, 8(5), 663-668 (in Russian)] 